\title{
BMJ Open Sociodemographic patterning of long-term diabetes mellitus control following Japan's 3.11 triple disaster: a retrospective cohort study
}

\author{
Claire Leppold, ${ }^{1,2}$ Masaharu Tsubokura, ${ }^{3}$ Akihiko Ozaki, ${ }^{4}$ Shuhei Nomura, ${ }^{5}$ \\ Yuki Shimada, ${ }^{6}$ Tomohiro Morita, ${ }^{7}$ Sae Ochi, ${ }^{7}$ Tetsuya Tanimoto, ${ }^{8}$ Masahiro Kami, ${ }^{9}$ \\ Yukio Kanazawa, ${ }^{3}$ Tomoyoshi Oikawa, ${ }^{3}$ Sarah Hill ${ }^{2}$
}

To cite: Leppold C, Tsubokura M, Ozaki A, et al. Sociodemographic patterning of long-term diabetes mellitus control following Japan's 3.11 triple disaster: a retrospective cohort study. BMJ Open 2016;6:e011455. doi:10.1136/bmjopen-2016011455

- Prepublication history for this paper is available online. To view these files please visit the journal online (http://dx.doi.org/10.1136/ bmjopen-2016-011455).

Received 9 February 2016 Revised 3 May 2016 Accepted 7 June 2016
CrossMark

For numbered affiliations see end of article.

Correspondence to

Claire Leppold;

cleppold@gmail.com

\section{ABSTRACT}

Objective: To assess the sociodemographic patterning of changes in glycaemic control of patients with diabetes affected by the 2011 triple disaster in Japan (earthquake, tsunami and nuclear accident).

Methods: A retrospective cohort study was undertaken with 404 patients with diabetes at a public hospital in Minamisoma City, Fukushima Prefecture. Glycated haemoglobin ( $\mathrm{HbA} 1 \mathrm{C})$ levels were measured in 2010, 2011 and 2012 to capture changes in glycaemic control postdisaster. Age, sex, urban/rural residency, evacuation status and medication use were also assessed.

Results: There was an overall deterioration in glycaemic control after the disaster, with the mean HbA1c rising from $6.77 \%$ in 2010 to $6.90 \%$ in 2012 (National Glycohemoglobin Standardization Program, NGSP). Rural residency was associated with a lower likelihood of deteriorating control (OR $0.34,95 \% \mathrm{Cl}$ 0.13 to 0.84 ), compared with urban residency. Older age (OR $0.95,95 \% \mathrm{Cl} 0.91$ to 0.98 ) was also slightly protective against increased HbA1c. Evacuation and sex were not significant predictors.

Conclusions: Patients with diabetes who were affected by Japan's triple disaster experienced a deterioration in their glycaemic control following the disasters. The extent of this deterioration was mediated by sociodemographic factors, with rural residence and older age protective against the effects of the disaster on glycaemic control. These results may be indicative of underlying social determinants of health in rural Japan.

\section{INTRODUCTION}

There is growing evidence that the development and progression of diabetes mellitus, a significant part of the global burden of noncommunicable diseases, ${ }^{1}$ is socially patterned. $^{2{ }^{3}}$ This fits with a broader literature on the social determinants of health, defined as the conditions in which "people are born,

\section{Strengths and limitations of this study}

- This study undertakes unprecedented assessment of the social predictors of diabetes outcomes in disaster settings.

- A considerable proportion of the study cohort $(20.8 \%)$ was lost to follow-up after the disasters.

- It was not possible to assess seasonal or temporal trends in glycated haemoglobin levels.

live, work and age'. ${ }^{2}$ Most prominently, low socioeconomic status has been linked with increased risk of developing diabetes, diabetes complications and diabetes-related mortality. ${ }^{4-9}$ Older age and male sex have also been found to be associated with higher risk of developing diabetes, ${ }^{10-12}$ and older adults are at higher risk of diabetes-related complications. ${ }^{13}$ On an area level, urban/ rural differences in diabetes prevalence ${ }^{14}$ and diabetes control ${ }^{15-17}$ have been observed, although there is little consistency between results from different countries.

Disasters are a phenomenon that may result in large-scale health impacts, including the worsened glycaemic control of patients with diabetes ${ }^{18} 19$ and increased incidence of diabetes-related mortality for months postdisaster. $^{20}{ }^{21}$ On 11 March 2011, Japan was hit by an earthquake, tsunami and nuclear disaster, referred to as the 3.11 triple disaster. This event had a dramatic impact on the health of the local population; in addition to the immediate burden in terms of injury and loss of life, there have been long-term effects on mental and physical health. ${ }^{22}{ }^{23}$ In terms of impacts on patients with diabetes, there have been mixed results. While worsened glycaemic control has been observed and attributed to psychological stress ${ }^{24}$ or changes in medication availability after the disasters, ${ }^{25}$ 
other studies have found no changes in glycaemic control. ${ }^{26}$ Until now, no research has examined the social patterning of diabetes outcomes after the 3.11 triple disaster, or any other disasters, despite the aforementioned evidence for social determinants of diabetes in non-disaster settings. This presents a notable gap in the literature where two fields of research, the social determinants of health and disaster medicine, have not yet intersected.

The aim of this study is to examine the impact of the 3.11 triple disaster on glycaemic control of patients with diabetes living in a significantly affected area, and to explore whether this impact varies by sociodemographic factors of age, sex, evacuation status and urban/rural residence.

\section{METHODS}

\section{Study setting and participants}

This study was carried out at Minamisoma Municipal General Hospital (MMGH), the only hospital to remain open within a $30 \mathrm{~km}$ radius of Fukushima Daiichi Nuclear Power Plant in the 4 weeks following the 3.11 triple disaster. Located $23 \mathrm{~km}$ away from the power plant, the hospital falls just outside of the mandatory evacuation zone ( $20 \mathrm{~km}$ radius) and inside the voluntary evacuation zone (20-30 km radius; figure 1$)$.

The target population for this study consisted of residents aged 20 or over who had known diabetes (type 1 and 2) and were under the treatment of MMGH before the 3.11 disasters. All patients undergoing diabetes care at the study hospital in 2010 were identified through billing records, and regarded as having a confirmed diagnosis of diabetes if a diagnosis was recorded in their chart, and there was a record of elevated glycated haemoglobin (HbA1c; above $6.3 \%$ by National Glycohemoglobin Standardization Program (NGSP) values) at any time in the previous 3 years. Inclusion criteria for this study were living in Minamisoma city, having had HbAlc levels measured within 3 months of

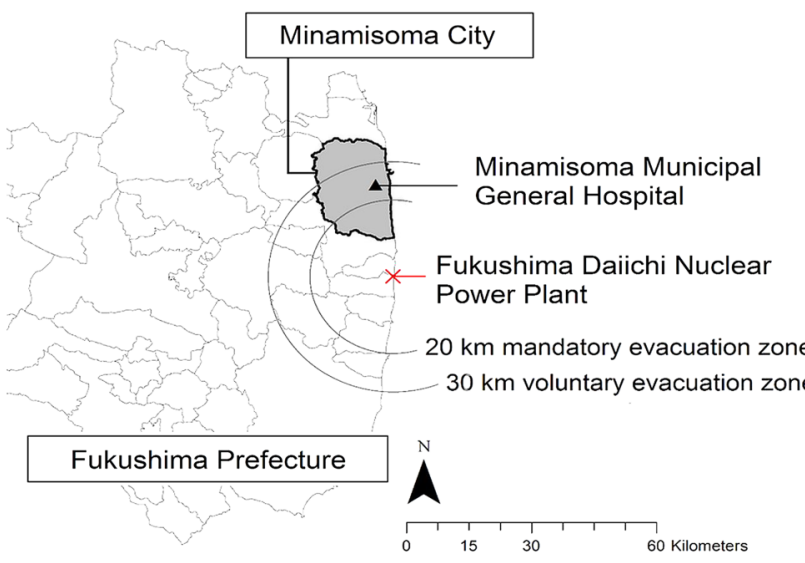

Figure 1 Location of Minamisoma Municipal General Hospital (MMGH) in relation to Fukushima Daiichi Nuclear Power Plant (created using ArcGIS V.10.2 software). the study baseline month (March 2010) and being in receipt of ongoing treatment predisaster (at least two check-ups in 2010) at MMGH. Of the 1332 patients with diabetes under care of the hospital in March 2010, 937 were resident in Minamisoma city and therefore eligible for inclusion in the study cohort. Of these, $533 \mathrm{did}$ not meet the criteria for HbAlc measurement or ongoing treatment, leaving a total of 404 patients who made up the study cohort at baseline. Of these 404 patients, 84 $(20.8 \%)$ were lost to follow-up after the disasters. Follow-up was complete for all three time points for 284 (70.3\%) of the study cohort, with postdisaster data only available from 1 year (2011 or 2012) for 36 (8.9\%).

\section{Study design and data collection}

The study attempted to capture: (1) changes in the proportion of patients with poor glycaemic control (based on HbAlc levels) from the predisaster to postdisaster period; and (2) what factors predicted a deterioration in glycaemic control. Glycaemic control was assessed at baseline (target date March 2010) and at two points postdisaster (target dates December 2011 and March 2012). Patients were regarded as having poor glycaemic control at a particular point in time if they had a recorded $\mathrm{HbA} 1 \mathrm{c} \geq 7.0 \% .{ }^{27} \mathrm{~A}$ deterioration in glycaemic control was defined as an $>0.5 \%$ increase in HbAlc, comparing predisaster and postdisaster measurements. Other study variables (age, sex, medication use, evacuation status and urban/rural residence) were based on information in the patient's outpatient hospital chart (birthdate, sex, prescribed medications, address). Residents of Minamisoma who evacuated the city for any length of time after the disasters had this information recorded in their hospital charts, which was used for study purposes.

Data on HbAlc levels were extracted from hospital laboratory records, with the laboratory's measurements using Japan Diabetes Society (JDS) values converted into the internationally recognised NGSP values. As above, HbA1c levels were assessed at three time points: March 2010 (predisaster), December 2011 (9 months postdisaster) and March 2012 (1 year postdisaster). One year predisaster (March 2010) was chosen as the baseline, while 9 months postdisaster (December 2011) was chosen as the first point for postdisaster measurement since a previous study has suggested that glycaemic control reaches its worst point 6-9 months following a disaster. $^{19}$ One year postdisaster (March 2012) was chosen as a second postdisaster comparison point. If multiple HbAlc levels had been tested in the same month, the date closest to the 11th of each month was used, in order to align most accurately to the timing of the disasters. If HbAlc data were not available for the postdisaster target month, the closest measurement of HbAlc was used. If participants did not have their HbAlc tested within 3 months of the 2011 and 2012 target months, they were regarded as lost to follow-up. 
Diabetes medication use was also recorded for each patient at each time period. Patients were categorised according to whether or not they had a change in their diabetes medication (including starting insulin, or an increase in the number of oral hypoglycaemic agents) following the 3.11 disasters.

Urban/rural residence was based on the patient's recorded address as of 2010. This was categorised as urban, semiurban or rural according to the average land price of the neighbourhood (cho-machi) in which they lived (obtained from the Minamisoma Municipal Local Government's Department of Health and Welfare), with higher land prices representing higher density urban areas while lower land prices corresponded with low-density semirural areas, including farmland and mountainous areas (figure 2). It was our initial intention to use average residential land price as a marker of patients' material wealth, but the geographic distribution of this variable made it clear that it was actually capturing the population density of various neighbourhoods within Minamisoma.

\section{Data analysis}

The proportion of patients with poor glycaemic control (HbA1c $\geq 7.0 \%)$ was calculated for each time point. The mean HbA1c level for each year was also calculated. The two outcomes were calculated twice, first based on all patients with data available for any of the relevant points in time $(n=404)$ and then based on a subcohort of patients $(n=284)$ with complete data at all three time points. The significance of changes over time in outcome measures was calculated using a $\chi^{2}$ test, and one-way analysis of variance followed by Bonferroni's post hoc test, respectively.

The proportion of patients experiencing deterioration in diabetes control was calculated, based on postdisaster compared with predisaster HbAlc levels (postdisaster: either 2011 or 2012).

We conducted logistic regression analyses to assess the risk factors associated with the postdisaster deterioration in diabetes control, adjusted for covariates. Since some patients had data at two postdisaster points (2011 and 2012), the regression models included a random effect at individual level to control for the fact that the same patients' data were correlated. Variables considered were sociodemographic factors, including year, age, sex, urban/rural residence, evacuation experience and change of insulin use or in the number of prescribed medicines after the disaster. We used model selection by backward-stepwise deletion with p-to-remove of $>0.05$, starting with all the candidate variables, until only significant variables were left, to obtain the final model that had the best fit to our data. Variables that were known or suspected risk factors (eg, evacuation) were incorporated into the final model regardless of their statistical significance. The partial F-test was used to verify for the entry and removal of variables from the model.

All statistical analyses were conducted using STATA/ MP V.13.

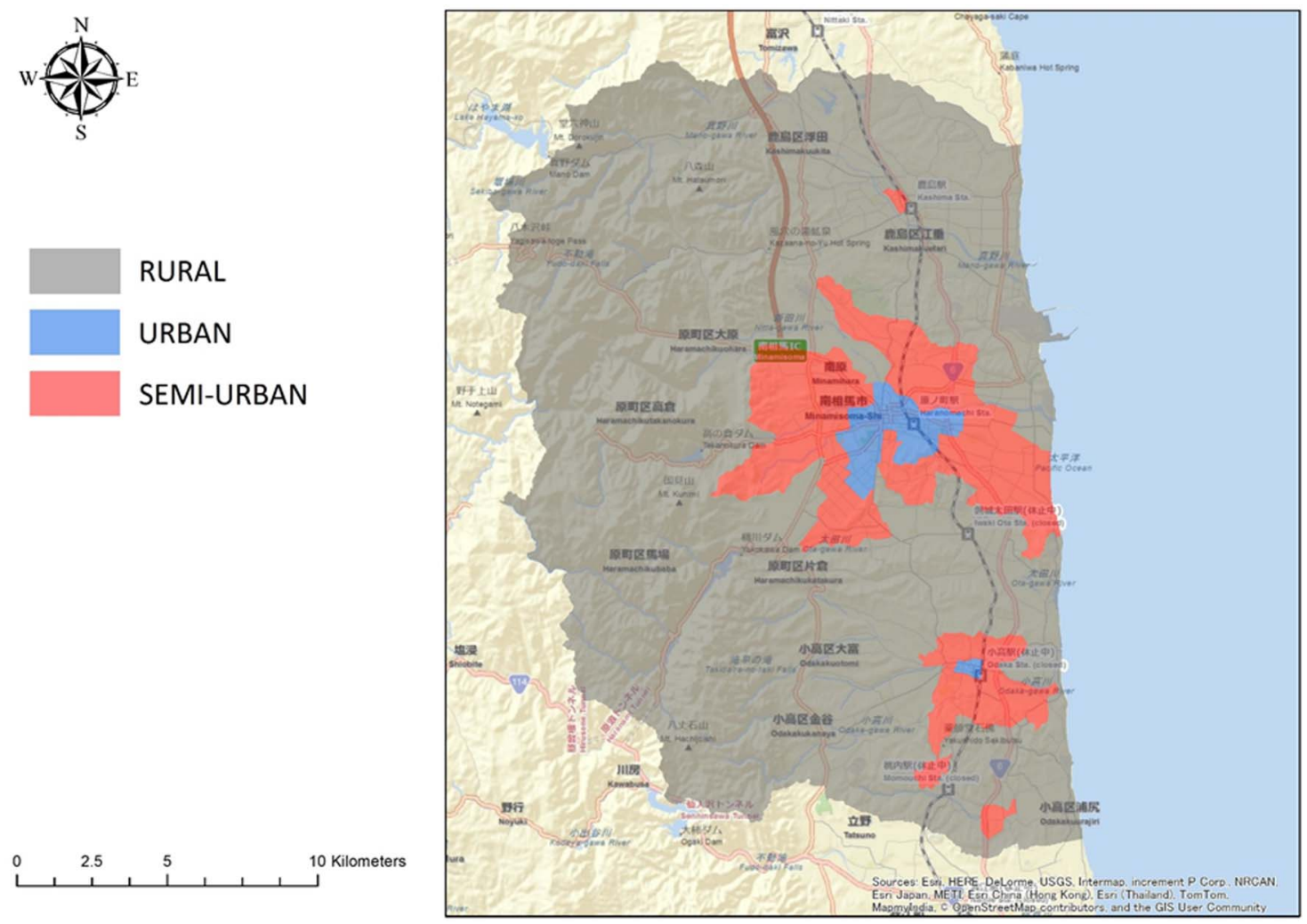

Figure 2 Classification of neighbourhoods by urbanity/rurality for Minamisoma City (created using ArcGIS V.10.2 software). 


\section{RESULTS}

\section{Cohort characteristics}

Characteristics of the overall study cohort are presented in the first column of table 1. Participants ranged in age from 35 to 104 years, with a preponderance in older age groups. The mean age in 2010 was 71 years. Age did not differ significantly by sex, evacuation status or urban/ rural residence. The majority of participants had type 2 diabetes, and there were slightly more men enrolled than women. About a third evacuated following the disasters.

While baseline data were available for 404 cohort members, we were unable to obtain any postdisaster data for almost one-quarter of the cohort $(n=84)$, who were therefore regarded as lost to follow-up and excluded from subsequent analyses. Complete follow-up (data for both postdisaster time points) was available for 284 of the remaining 320 cohort members, with data from only one postdisaster time point available for 36 individuals (figure 3). The characteristics of the 284 individuals with complete follow-up, and of the 84 individuals lost to follow-up, are shown in the second and third columns of table 1. Patients lost to follow-up were more likely to have evacuated after the disasters $(\mathrm{p}<0.001)$.

\section{Changes in diabetes control}

Control of diabetes deteriorated postdisaster, with the mean HbA1c level increasing in each year, in addition to the proportion of patients with poor glycaemic control (HbAlc $\geq 7.0 \%$; figure 4). On the basis of cohort members with available data at each point in time, the mean $\mathrm{HbAlc}$ was $6.77(\mathrm{SD}=0.78)$ in $2010(\mathrm{n}=404), 6.85$ $(\mathrm{SD}=0.83)$ in $2011(\mathrm{n}=300)$ and $6.90 \quad(\mathrm{SD}=0.88)$ in 2012 $(n=304)$. The same pattern exists when analysis is limited to the subcohort with complete follow-up data $(\mathrm{n}=284)$, for which the mean HbAlc was $6.76(\mathrm{SD}=0.69)$ in 2010, $6.87(\mathrm{SD}=0.83)$ in 2011 and $6.93(\mathrm{SD}=0.87)$ in 2012. The proportion of participants with poor glycaemic control (HbA1c of $\geq 7.0 \%$ ) increased significantly from $31.9 \%$ in 2010 to $41.4 \%$ in 2012 ( $p=0.028$; figure 4). Again, the same pattern was observed when analysis was limited to patients with complete follow-up $(\mathrm{n}=284)$.

There was no statistically significant difference in the proportion of patients using insulin or the proportion using more than one type of oral antihyperglycaemic agents across the three time points.

Overall, $66.5 \% \quad(n=213)$ of followed patients $(n=320)$ experienced a deterioration in their diabetes control postdisaster (HbAlc increase by $>0.5 \%$ in either 2011 or 2012), although not all met the criteria for "poor control' as their $\mathrm{HbAlc}$ remained $<7.0 \%$ even after increases. In 2011, 57.5\% of patients had higher HbA1c levels compared with predisaster (based on 304 patients with available data), while in 2012 this proportion was $53.0 \%$ (based on 300 patients with available data).

\section{Influence of sociodemographic factors on diabetes control}

Results of regression analyses suggest that sociodemographic factors influenced the extent to which glycaemic control deteriorated in the postdisaster period ( $\mathrm{HbAlc}$ increase by $>0.5 \%$ in either 2011 or 2012; table 2). Deterioration of glycaemic control was patterned significantly by age and insignificantly by sex, with increased age found to be slightly protective (OR $0.95, p \leq 0.01$, for each additional year of age) and females at lower odds of deterioration compared with males (OR 0.50, $\mathrm{p}=0.06$ ). Evacuation was not a statistically significant

Table 1 Characteristics of the overall study cohort $(n=404)$, the subcohort with complete follow-up $(n=284)$ and individuals lost to follow-up $(n=84)$

\begin{tabular}{|c|c|c|c|}
\hline Characteristics & $\begin{array}{l}\text { Overall } \\
(\mathrm{N}=404)\end{array}$ & $\begin{array}{l}\text { Complete } \\
(\mathrm{N}=284)\end{array}$ & $\begin{array}{l}\text { Lost } \\
(\mathrm{N}=84)\end{array}$ \\
\hline Age range & $(35-104)$ & $(36-92)$ & $(35-103)$ \\
\hline Mean age at 2010 (mean, SD) & $71.0(10.6)$ & $70.7(9.7)$ & $71.0(12.8)$ \\
\hline \multicolumn{4}{|l|}{$\operatorname{Sex}(N, \%)$} \\
\hline Male & $224(55.5)$ & $156(54.9)$ & $53(63.1)$ \\
\hline Female & $180(44.6)$ & $128(45.1)$ & $31(36.1)$ \\
\hline \multicolumn{4}{|l|}{ Diabetes type (N, \%) } \\
\hline Type 1 & $3(0.7)$ & $2(0.7)$ & $1(1.2)$ \\
\hline Type 2 & 369 (91.3) & $259(91.2)$ & $77(91.7)$ \\
\hline NA & $32(7.1)$ & $23(8.1)$ & $6(7.1)$ \\
\hline \multicolumn{4}{|l|}{ Urban/rural residence $(\mathrm{N}, \%)$} \\
\hline Urban & $140(34.7)$ & $97(34.2)$ & $26(31.0)$ \\
\hline Semiurban & $131(32.4)$ & $94(33.1)$ & $28(33.3)$ \\
\hline Rural & $133(32.9)$ & 93 (32.8) & $30(25.7)$ \\
\hline \multicolumn{4}{|l|}{ Evacuation (N, \%) } \\
\hline Evacuated & $131(32.4)$ & 93 (33.2) & $27(61.4)$ \\
\hline Did not evacuate & $223(55.2)$ & $187(66.8)$ & $17(38.6)$ \\
\hline NA & $50(12.3)$ & $4(1.4)$ & $40(47.6)$ \\
\hline
\end{tabular}




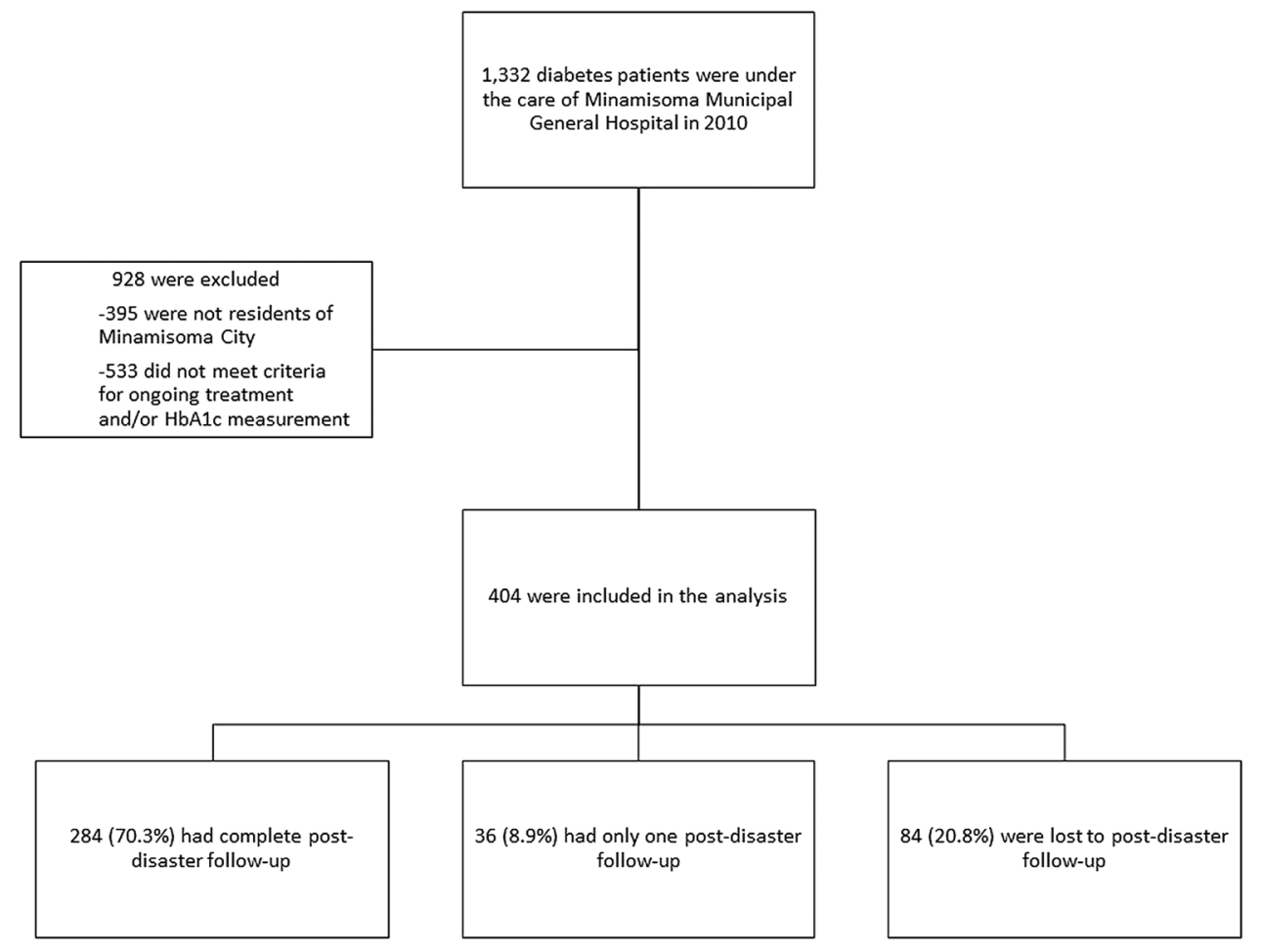

Figure 3 Participant inclusion and follow-up. HbA1c, glycated haemoglobin.

predictor of deteriorating glycaemic control postdisaster. Those residing in rural areas had the lowest odds of deteriorating glycaemic control postdisaster (OR 0.34, $\mathrm{p} \leq 0.05)$, and those living in semiurban areas also appeared to experience a non-significant protective effect compared with patients living in the most urban neighbourhoods.

The adjusted ORs presented here are derived from the final regression model (adjusting for year of follow-up, age, sex, urban/rural residence and evacuation status). Almost identical results were obtained when changes in diabetes medication (insulin and oral hypoglycaemics) were also included in the model.

\section{DISCUSSION}

This study finds a general deterioration in the glycaemic control of patients with diabetes in Minamisoma city,

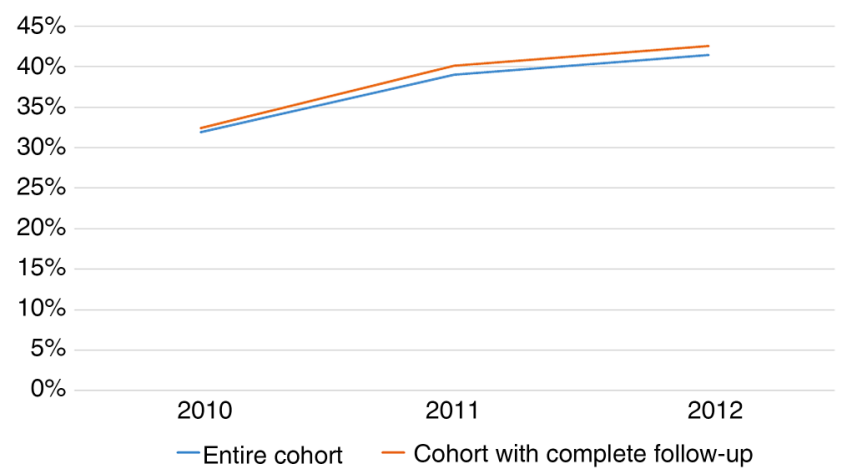

Figure 4 Percentage of patients with poor glycaemic control $(\mathrm{HbA} 1 \mathrm{c} \geq 7.0 \%)$ by year. HbA1c, glycated haemoglobin.
Fukushima prefecture, following the 3.11 triple disaster. Increased proportions of patients with diabetes with HbAlc $\geq 7.0 \%$ were observed at both 9 and 12 months, and $66.5 \%(n=213)$ of followed patients $(n=320)$ experienced an increase in $\mathrm{HbA} 1 \mathrm{c}>0.5 \%$ following the disasters. These results are consistent with previous studies which have found increased HbAlc levels of patients with diabetes following natural disasters. ${ }^{18} 19$

Furthermore, this study finds that postdisaster deterioration of diabetes was patterned by sociodemographic factors. Urban/rural residency was a strong predictor of postdisaster glycaemic deterioration (HbAlc increase of $>0.5 \%$ ), with rural residency associated with the lowest

\begin{tabular}{|c|c|c|}
\hline Variable & OR (95\% Cl) & p Value \\
\hline \multicolumn{3}{|l|}{ Year } \\
\hline 2011 & Ref & \\
\hline 2012 & 1.54 (0.96 to 2.38$)$ & 0.07 \\
\hline \multicolumn{3}{|l|}{ Sex } \\
\hline Male & Ref & \\
\hline Female & $0.50(0.25$ to 1.02$)$ & 0.06 \\
\hline Age & $0.95(0.91$ to 0.98$)$ & $<0.01$ \\
\hline \multicolumn{3}{|c|}{ Urban/rural residence $(\mathrm{N}, \%)$} \\
\hline Urban & Ref & \\
\hline Semiurban & $0.76(0.32$ to 1.78$)$ & 0.53 \\
\hline Rural & $0.34(0.13$ to 0.84$)$ & $<0.05$ \\
\hline \multicolumn{3}{|l|}{ Evacuation } \\
\hline No & Ref & \\
\hline Yes & $1.08(0.50$ to 2.35$)$ & 0.83 \\
\hline
\end{tabular}


odds of deterioration (OR 0.34, CI 0.13 to 0.84 , $\mathrm{p} \leq 0.05)$. Previous literature has suggested that urban/ rural residency can influence the HbAlc levels of patients with diabetes in non-disaster settings, yet there are diverse findings between countries. In Germany, mean HbA1c levels of patients with diabetes were shown to be lower in urban areas, ${ }^{15}$ while a study from Fiji found the opposite result ${ }^{16}$ and a study from the USA determined no associations between urban/rural residency and HbA1c levels. ${ }^{17}$ The impact of urban/rural residency on glycaemic control is most likely mediated by sociocultural factors, thus differing by country. The present results highlight a need for further research on the underlying factors involved in effects of urban/rural residency on glycaemic control in disaster and nondisaster settings.

The results of this study also indicated that each year of increased age had a small protective effect against postdisaster deterioration (OR $0.95,95 \%$ CI 0.01 to 0.98 , $\mathrm{p}=0.01)$. It is worth noting the advanced age of this cohort (mean age of 71 years in 2010), reflecting the rapid population ageing of Minamisoma City. ${ }^{28}$ While older age is generally linked with an increased risk of developing diabetes, ${ }^{11} 16$ it has been found in nondisaster settings that older adults are more likely to meet HbA1c goals than younger adults, ${ }^{29}$ and the results of this study indicate that they may also be less likely to experience HbAlc deterioration following disasters. This finding conflicts with the concept that the elderly are some of the most vulnerable to disaster impacts on chronic diseases, ${ }^{30}$ and deserves further research.

In addition to its relevance to research on postdisaster health outcomes, this research provides a case study of the social determinants of health in rural Japan, considering the 3.11 triple disaster as an external stressor that may highlight underlying patterns of advantage and disadvantage. There has been limited work on the social determinants of health in Japan. Until now, the majority of this research has come from the USA, the UK and Canada, and studies assessing health inequalities in Japan often rely on measurements developed in these countries such as income and occupational indicators; ${ }^{31} 32$ many focus on the end point of mortality, and we could find none that have assessed determinants of diabetes outcomes. A limitation in applying measurements developed in other countries is that there has been little theoretical exploration of the most fitting social indicators for the unique sociocultural context of Japan. This is a contrast to other countries, where measurements such as deprivation indices have been developed and validated, ${ }^{31}$ presenting a need for further research. The present findings on age and rural residency may hold insight on the social determinants of health in Japan. While this study is limited in that it cannot account for underlying causes of glycaemic differences related to urban/rural residency and age, it highlights the need for further studies on social patterns of health and disease in Japan and illustrates that these indicators may be meaningful. Age is a particularly relevant finding in regard to this rapidly ageing society, and has been discussed as a vulnerability factor in previous studies from Japan. ${ }^{33}$ Our finding of age as slightly protective deserves further research, in addition to deepened inquiry on urban/rural differences in health.

\section{Strengths and limitations of this study}

A key limitation of our study was the considerable proportion of the study cohort lost to follow-up (20.8\%). From available hospital data, it was not possible to determine why these patients had not had HbAlc measured after the disasters. Comparison with the characteristics of the cohort as a whole and those with complete follow-up (table 1) suggests that patients lost to follow-up had similar characteristics to those who remained in the study, thus reducing the likelihood of selection bias. Nevertheless, this reduced the overall study power and may have limited our ability to detect small associations. It is likely that patients lost to follow-up were those most significantly affected by the disaster, for example, through losing a home or a family member. Since stress is hypothesised as a key pathway through which disaster experience leads to deterioration of glycaemic control, the loss of the most disaster-affected patients may have biased results towards the null (ie, resulted in a more conservative estimation of the impact of the disaster on glycaemic control). It is possible that this loss to follow-up at least partly accounts for our failure to find an association between evacuation status and glycaemic control; while this may represent a genuine lack of effect, we note that previous research found that evacuees were at increased risk of developing diabetes. ${ }^{34}$ Moreover, it is additionally possible that evacuation status may have been misclassified for some of our cohort, since our measure was based on hospital records which made no distinction between short-term and longterm evacuation. Although this study was carried out in an area impacted by a nuclear disaster, it was not possible to assess radiocontamination levels and any possible correlations with glycaemic control. Additionally, it was not possible to assess seasonal or temporal trends in HbAlc levels because of the limited time points assessed in this study.

Despite these limitations, this study provides a valuable analysis of glycaemic control in a defined cohort of patients with diabetes affected by the 3.11 triple disaster. This is the first study to suggest that the impact of a disaster on glycaemic control is mediated by sociodemographic factors.

\section{CONCLUSION}

Patients with known diabetes who were living in Minamisoma at the time of Japan's 3.11 triple disaster experienced a deterioration in glycaemic control. This deterioration was patterned by sociodemographic factors, with urban residency and younger age associated 
with higher odds of increased HbAlc levels postdisaster. Findings from this study may be useful in identifying patients with diabetes at increased risk in postdisaster contexts. These results could additionally be valuable to future studies addressing the social determinants of health in Japan.

\section{Author affiliations}

${ }^{1}$ Department of Research, Minamisoma Municipal General Hospital, Minamisoma, Japan

${ }^{2}$ Global Public Health Unit, School of Social and Political Science, University of Edinburgh, Edinburgh, UK

${ }^{3}$ Department of Radiation Protection, Minamisoma Municipal General

Hospital, Minamisoma, Japan

${ }^{4}$ Department of Surgery, Minamisoma Municipal General Hospital,

Minamisoma, Japan

${ }^{5}$ Department of Epidemiology and Biostatistics, School of Public Health,

Imperial College London, London, UK

${ }^{6}$ Department of Neurosurgery, Minamisoma Municipal General Hospital, Minamisoma, Japan

${ }^{7}$ Department of Internal Medicine, Soma Central Hospital, Fukushima, Japan

${ }^{8}$ Department of Internal Medicine, Jyoban Hospital of Tokiwakai Group, Iwaki, Japan

${ }^{9}$ Medical Governance Research Institute, Tokyo, Japan

Acknowledgements The authors thank the staff at Minamisoma Municipal General Hospital for their cooperation with this study. In particular, they acknowledge Masatsugu Tanaki and Tatsuya Shishido. They also thank the Minamisoma Municipal Local Government's Department of Health and Welfare. They also thank Dr Sudeepa Abeysinghe for comments on an earlier draft of this work.

Contributors CL, MT, AO, TM, SO, TT, SH, MK, YK and TO conceptualised and designed the study. CL, AO and YS contributed to data collection and quality control. SN analysed the data. CL wrote the manuscript and all authors contributed to its revision.

Funding This research received no specific grant from any funding agency in the public, commercial or not-for-profit sectors.

Competing interests None declared.

Ethics approval The study was reviewed and approved by the Minamisoma Municipal General Hospital Institutional Review Board on 14 May 2015.

Provenance and peer review Not commissioned; externally peer reviewed.

Data sharing statement No additional data are available.

Open Access This is an Open Access article distributed in accordance with the Creative Commons Attribution Non Commercial (CC BY-NC 4.0) license, which permits others to distribute, remix, adapt, build upon this work noncommercially, and license their derivative works on different terms, provided the original work is properly cited and the use is non-commercial. See: http:// creativecommons.org/licenses/by-nc/4.0/

\section{REFERENCES}

1. World Health Organization (WHO). Global status report on noncommunicable diseases 2010. http://www.who.int/nmh/ publications/ncd_report2010/en/ (accessed 1 Feb 2016).

2. Walker RJ, Smalls BL, Campbell JA, et al. Impact of social determinants of health on outcomes for type 2 diabetes: a systematic review. Endocrine 2014;47:29-48.

3. Clark ML, Utz SW. Social determinants of type 2 diabetes and health in the United States. World J Diabetes 2014;5:296-304.

4. Everson SA, Maty SC, Lynch JW, et al. Epidemiologic evidence for the relation between socioeconomic status and depression, obesity, and diabetes. J Psychosom Res 2002;53:891-5.

5. Ross NA, Gilmour H, Dasgupta K. 14-year diabetes incidence: the role of socio-economic status. Health Rep 2010;21:19-28.

6. Collier A, Ghosh S, Hair M, et al. Impact of socioeconomic status and gender on glycaemic control, cardiovascular risk factors and diabetes complications in type 1 and 2 diabetes: a population based analysis from a Scottish region. Diabetes Metab 2015;41:145-51.

7. Saydah S, Lochner K. Socioeconomic status and risk of diabetesrelated mortality in the US. Public Health Rep 2010;125:377-88.

8. Walker JJ, Livingstone SJ, Colhoun HM, et al. Effect of socioeconomic status on mortality among people with type 2 diabetes: a study from the Scottish Diabetes Research Network Epidemiology Group. Diabetes Care 2011;34:1127-32.

9. Rawshani A, Svensson AM, Rosengren A, et al. Impact of socioeconomic status on cardiovascular disease and mortality in 24,947 individuals with type 1 diabetes. Diabetes Care 2015;38: 1518-27.

10. Poulsen K, Cleal B, Willaing I. Diabetes and work: 12-year national follow-up study of the association of diabetes incidence with socioeconomic group, age, gender and country of origin. Scand $J$ Public Health 2014;42:728-33.

11. Nayak BS, Sobrian A, Latiff $K$, et al. The association of age, gender, ethnicity, family history, obesity and hypertension with type 2 diabetes mellitus in Trinidad. Diabetes Metab Syndr 2014;8:91-5.

12. Vega T, Gil M, Lozano J. Age and sex differences in the incidence of diabetes mellitus in a population-based Spanish cohort. $J$ Diabetes 2015;7:411-17.

13. Chew BH, Ghazali SS, Ismail M, et al. Age $\geq 60$ years was an independent risk factor for diabetes-related complications despite good control of cardiovascular risk factors in patients with type 2 diabetes mellitus. Exp Gerontol 2013;48:485-91.

14. Lee HY, Won JC, Kang YJ, et al. Type 2 diabetes in urban and rural districts in Korea: factors associated with prevalence difference. J Korean Med Sci 2010;25:1777-83.

15. Sämann A, Kaiser J, Hunger-Dathe W, et al. Population-based measurement of quality of diabetes care using $\mathrm{HbA} 1 \mathrm{c}$ values in the state of Thuringia/Germany. Exp Clin Endocrinol Diabetes 2004;112:531-7.

16. Russell-Jones DL, Hoskins $\mathrm{P}$, Kearney E, et al. Rural/urban differences of diabetes-impaired glucose tolerance, hypertension, obesity, glycosylated haemoglobin, nutritional proteins, fasting cholesterol and apolipoproteins in Fijian Melanesians over 40. $Q$ J Med 1990;74:75-81.

17. Egede LE, Gebregziabher M, Hunt KJ, et al. Regional, geographic, and racial/ethnic variation in glycemic control in a national sample of veterans with diabetes. Diabetes Care 2011;34:938-43.

18. Cook CB, Wellik KE, Fowke M. Geoenvironmental diabetology. $J$ Diabetes Sci Technol 2011;5:834-42.

19. $\mathrm{Ng} J$, Atkin SL, Rigby AS, et al. The effect of extensive flooding in Hull on the glycaemic control of patients with diabetes. Diabet Med 2011;28:519-24.

20. Hendrickson LA, Vogt RL. Mortality of Kauai residents in the 12-month period following Hurricane Iniki. Am J Epidemiol 1996;144:188-91.

21. McKinney N, Houser C, Meyer-Arendt K. Direct and indirect mortality in Florida during the 2004 hurricane season. Int J Biometeorol 2011;55:533-46.

22. Tsubokura M, Hara K, Matsumura T, et al. The immediate physical and mental health crisis in residents proximal to the evacuation zone after Japan's nuclear disaster: an observational pilot study. Disaster Med Public Health Prep 2014;8:30-6.

23. Hasegawa A, Tanigawa K, Ohtsuru A, et al. Health effects of radiation and other health problems in the aftermath of nuclear accidents, with an emphasis on Fukushima. Lancet 2015;386:479-88.

24. Fujihara K, Saito A, Heianza Y, et al. Impact of psychological stress caused by the Great East Japan Earthquake on glycemic control in patients with diabetes. Exp Clin Endocrinol Diabetes 2012;120:560-3.

25. Ogawa S, Ishiki M, Nako K, et al. Effects of the Great East Japan earthquake and huge tsunami on glycaemic control and blood pressure in patients with diabetes mellitus. BMJ Open 2012;2: e000830.

26. Nishikawa $Y$, Fukuda $Y$, Tsubokura $M$, et al. Managing type 2 diabetes mellitus through periodical hospital visits in the aftermath of the Great East Japan earthquake disaster: a retrospective case series. PLOS ONE 2015;10:e0125632.

27. American Diabetes Association. Standards of medical care in diabetes-2016. Diabetes Care 2016;39(Suppl 1):S4-S5.

28. Ishikawa K, Kanazawa Y, Morimoto S, et al. Depopulation with rapid aging in Minamisoma City after the Fukushima Daiichi nuclear power plant accident. J Am Geriatr Soc 2012;60:2357-8.

29. Stark Casagrande S, Fradkin JE, Saydah SH, et al. The prevalence of meeting $\mathrm{A} 1 \mathrm{C}$, blood pressure, and LDL goals among people with diabetes, 1988-2010. Diabetes Care 2013;36:2271-9. 
30. Aldrich N, Benson WF. Disaster preparedness and the chronic disease needs of vulnerable older adults. Prev Chron Dis 2008;5: A27.

31. Fukuda $\mathrm{Y}$, Nakao $\mathrm{H}$, Yahata $\mathrm{Y}$, et al. Are health inequalities increasing in Japan? The trends of 1955 to 2000. Bio Sci Trends 2007;1:38-42.

32. Suzuki E, Kashima S, Kawachi I, et al. Social and geographic inequalities in premature adult mortality in Japan: a multilevel observational study from 1970 to 2005. BMJ Open 2012;2:e000425.

33. Muramatsu N, Akiyama H. Japan: super-aging society preparing for the future. Gerontologist 2011;51:425-32.

34. Satoh $\mathrm{H}$, Ohira $\mathrm{T}$, Hosoya $\mathrm{M}$, et al. Evacuation after the Fukushima Daiichi nuclear power plant accident is a cause of diabetes: results from the Fukushima Health Management Survey. J Diabetes Res 2015;2015:627390. 